Research

\title{
A framework for systemic sustainable construction industry development (SSCID)
}

\author{
William Gyadu-Asiedu' ${ }^{1}$ Adwoa Ampadu-Asiamah ${ }^{2} \cdot$ Alfred Fokuo-Kusi $^{3}$
}

Received: 18 December 2020 / Accepted: 12 April 2021

Published online: 24 May 2021

(c) The Author(s) 2021 OPEN

\begin{abstract}
The quest for construction industry $(\mathrm{Cl})$ development in developing countries has met with several challenges. These challenges are numerous and varied. The study aimed to provide a framework by which the construction industry development agenda in developing countries could be prosecuted through a more structured and systemic approach. The qualitative research approach was adopted for the study. This approach was employed within the constructivist epistemological paradigm. Regarding information gathering, the study used the integrative literature review approach to elucidate the construction industry's nature and its proper systemic context. Complexity, interconnectedness, fragmentation, culture, and informality were found to be common challenges inherent in most $\mathrm{Cls}$. Concerning the development of the industry, the approach was to (1) consider the industry as a system of systems (enabling the use of the principles of systems thinking and systems engineering), (2) apply the concepts of sustainable development as considered within the sustainable development goals (SDGs) and specified in the triple-bottom-line (TBL), i.e., the economic, environmental, and social dimensions, (3) identify the components of $\mathrm{Cl}$ development (eight components were identified), which are: technology development, corporate development, human resource development, institutional development, material development, documentation, practice and procedure, and operating environment), and (4) Integrated studies. A conceptual framework was modelled from all the identified constructs. Based on this model, it was possible to propose a framework for assessing the maturity level of a country's sustainable construction industry development and, thereby, monitor its systemic development.
\end{abstract}

Keywords Construction industry · Sustainable construction · System thinking · SDGs · Maturity framework

\section{Introduction}

Construction industry development has been a global agenda. Developing countries at various development levels have put in efforts towards this objective [1, 2]. However, much has not been achieved due to several challenges facing the construction industries. According to Gyadu-Asiedu [3], most of the problems militating against achieving the desired effect on any country's construction industry have to do with the project execution challenges. The common problems of low productivity, delays, and cost overrun have been nearly over-researched with very related results (e.g., [4-7]). Windapo and Cattell [8] undertook a literature review research and identified 12 perceived challenges facing the South African Construction industry as follows: (i) Public-sector capacity, (ii) Mismatches between available skills and required

William Gyadu-Asiedu, willgyas@ktu.edu.gh; Adwoa Ampadu-Asiamah, nana.difie@gmail.com; Alfred Fokuo-Kusi, alfred_kofi@ yahoo.co.uk| ${ }^{1}$ Koforidua Technical University, P.O. Box 981, Koforidua, Ghana. ${ }^{2}$ Accra Technical University, Barnes Road, P.O. GP 561, Accra, Ghana. ${ }^{3}$ Sunyani Technical University, P.O. Box 206, Sunyani, Ghana.

Discover Sustainability $\quad$ (2021) 2:25 | https://doi.org/10.1007/s43621-021-00033-y 
skills, (iii) Globalisation/critical global issues, (iv) Procurement practices and the capacity for sustainable empowerment, (v) Access to affordable mortgage/credit and interest rates, (vi) Poverty, (vii) Technology, (viii) Availability of suitable land for construction, (ix) Availability of Infrastructure, (x) High rate of failure of enterprises, (xi) Increases in the costs of building materials, and (xii) Statutes and regulations. Results from other countries are very much related to these [9-12].

After several years of conferences, workshops, and reports by workgroups on the construction industry in developing countries, the International Council for Research and Innovation for Building and Construction (CIB) identified the following as the main challenges facing the construction industry in developing countries [13]: (i) The need for a new model of development, (ii) Linkages between urban and rural development, (iii) The need for sustainable housing, (iv) Sustainable education, (v) Sustainable construction through innovative building materials and methods, (vi) Indigenous technologies in the modern era, (vii) Bridging the gender divide, (viii) Appropriate financing and delivery systems, (ix) Issues of governance and management across the industry, (x) Appropriate procurement systems, (xi) Project management, (xii) Access for Local Firms. These and other challenges have impeded the progress being made towards many developing countries' $\mathrm{Cl}$ developmental agenda. The problems are nearly common to most developing countries but with varying degrees of intensity. Others have considered the inherent nature of the industry and identified key challenges, including the following: fragmentation [14], complexity [15] and interconnectedness [16], informality [17], and the impact of culture [18]. These are considered the core challenges since they are common to all Cls.

However, the preceding suggests that each industry must clarify its myriads of problems through a taxonomy of structural challenges. This taxonomy is recommended as the first step towards any structural-developmental programme. The reason is that developing the industry has to be done with restructuring, re-engineering, and re-modelling. However, there are also issues about the approaches being used to achieve construction industry development.

\section{The need for a sustainable construction industry development maturity framework}

The absence of Systems Thinking in the solution package for these core challenges facing the industry indicates a significant $\mathrm{Cl}$ research gap. Also, efforts at sustainable construction have not met the desired expectations over the years [19]. Problems militating against sustainable construction include cultural, governmental, institutional, technology, legislation, cost, capacity and knowledge, and cooperation [20-25]. Concerns have also been raised about the lack of appropriate tools to measure and monitor sustainability $[26,27]$. The thrust of the matter is that it is difficult to ascertain the following vital positions regarding a specific construction industry:

i. The extent to which the construction industry of a country has successfully pursued its development agenda.

ii. The extent to which this development has included sustainability.

iii. The process of measuring, monitoring, and managing a construction industry's maturity level over the years.

It is impossible to know the level of development a construction industry has reached at any point in time. Ofori [2] has said that the absence of measurable performance targets is one reason why there is a lack of progress in the industry's development programmes.

In light of these challenges, this study aimed to provide a framework by which a more structured and systemic approach could prosecute construction industry development agendas in developing countries.

\section{Methodology}

The study used the qualitative research approach in its inquiry. The constructivist epistemological paradigm underpinned this approach. Such concepts as system thinking and sustainable development (emphasising the economic, environmental, and social pillars) were employed as an invaluable tool for the study's scope definition. Regarding the methods of information gathering and analyses, the study used the review research strategy to analyse existing literature to elucidate the various aspects of the construction industry that needs to be considered for its systemic, sustainable development. The process involved examining extant literature to systematically identify contents in terms of pre-known and anticipated classes of knowledge [28]. The review of existing literature is a recognised and well-accepted way of knowledge expansion [29]. This process has been used as a methodology in various research 
areas. For example, Mahamid [30] used it for researching construction business failures. In contrast, Ofori [31] used it as a methodology to study the nature of the construction industry, its needs, and development over a decade. According to Snyder [32], this approach has been used in business research citing such examples as in Covington [33], Gross [34], and Mazumdar et al. [35].

The integrative approach of the review research was used. It involved undertaking an overview, an assessment, a reconceptualisation, and a synthesis of the literature on the chosen topic in a way that enables new theoretical frameworks and perspectives to emerge $[32,36]$.

The process of selecting publications for the study followed three strategic approaches. The information on construction industry development and its challenges received a broad consultation of literature, primarily. However, a deliberate attempt was also made to focus more on researchers in this field of study, especially those focused on developing countries. Regarding the review on other variables of the construction industry system, the publications' selection was a bit more controlled based on the study's focus.

For the information on system thinking, the approach was to allow for backward integration of knowledge that dates back to the earliest relevant writings on system thinking and the general systems theories. The aim was to identify the study with the 'roots' of the concept. Regarding the concept of sustainability and sustainable construction, the approach was to identify the link between the sustainable development goals (SDGs), the pillars of sustainable construction, also called the triple bottom line (TBL), and construction industry development goals. Identifying these was seen as a critical part of the study. The reason being that, in the opinion of the authors, development should have everything to do with sustainability. This position is especially so in the era of the SDGs.

Thus, several library databases were used to search and collect references for this review, including Science Direct, Taylor \& Francis, Springer, Wiley, and McGraw-Hill.

Figure 1 shows the methodology used in selecting the articles and the conduct of the study.

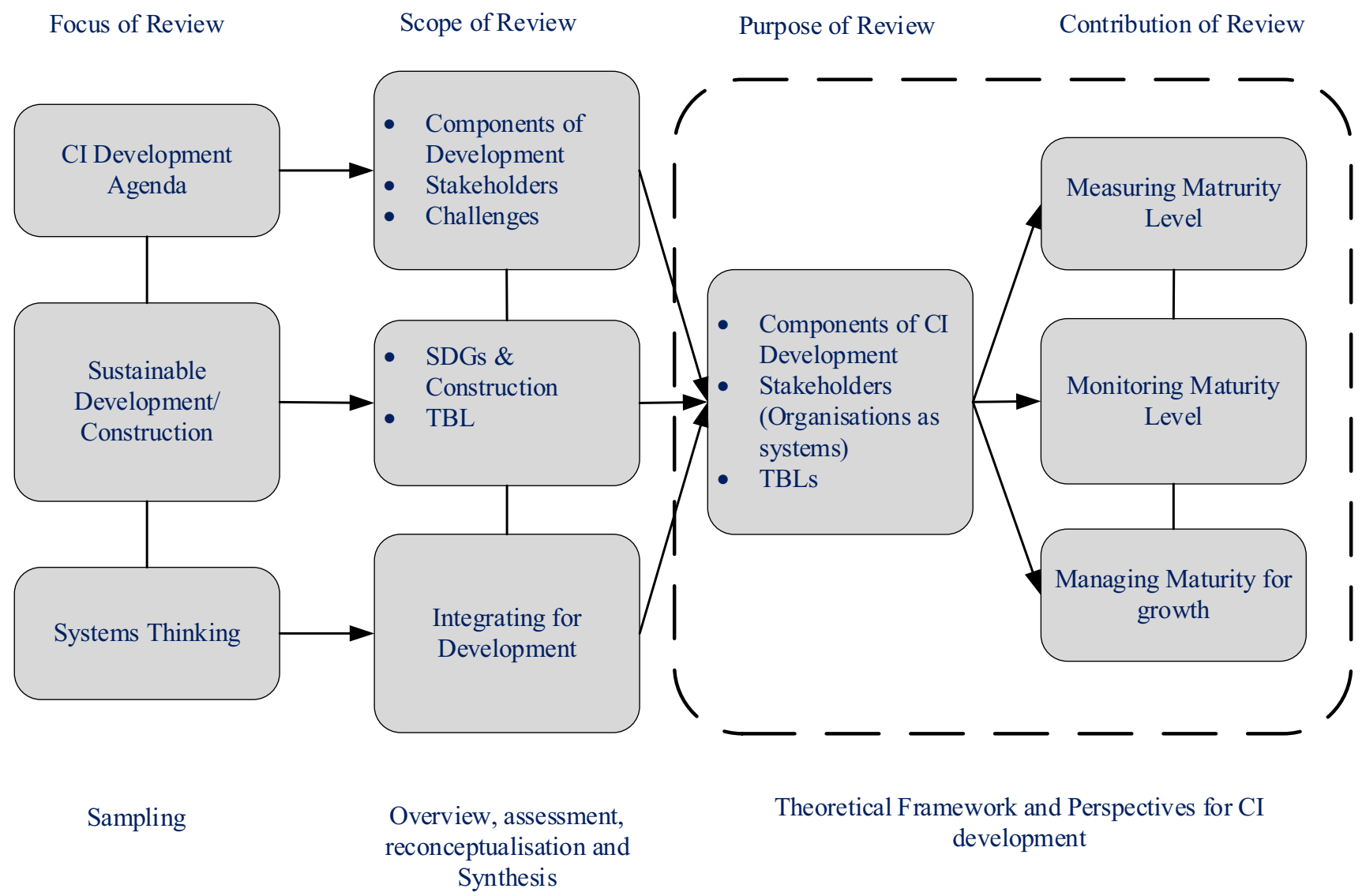

Fig.1 Methodological framework for the study 


\subsection{Constructivism and the identification of the main constructs for the study}

The constructivist epistemology posits that humans generate knowledge and meaning from an interaction between their experiences, ideas, and existing knowledge. Based on this epistemology, it was decided to categorise the study into four stages. Stage one yielded the main challenges as captured in the introduction and the problem statement of this paper. Stages two and three yielded the constructs that form the basis of the study's conceptual framework. Stage four provided the information used in modelling the framework for assessing the industry's maturity level.

i. Identifying the critical challenges confronting the construction industry development agenda.

ii. Identifying tools for structuring and defining the problem.

iii. Identifying the parts of the industry.

iv. Developing a maturity framework for $\mathrm{Cl}$ development.

The first three were the focus of the review study. The final stage was the synthesis stage, where the constructs were integrated into a conceptual and a maturity framework.

1. First stage: identifying the challenges facing the $\mathrm{Cl}$

This stage of the review identified the critical challenges militating against the construction industry in several countries. At this stage, it was found that various researchers identified challenges as they prevail in their area of study. However, it was possible, through qualitative value judgement, to categorise them to (i) those inherent in the industry and (ii) those imposed by institutional weaknesses and other external factors.

2. Second stage: identifying the tools for the study

At this stage, it was necessary to identify the relevant tools for structuring the problem the study seeks to address. The following were identified as essential tools:

- Systems thinking, systems engineering: to address the problem relating fragmentation and interconnectedness, culture and informality, and also to and to clarify the nature of the industry

- Sustainable development principles (the TBL and the SDGs): to address the industry's development aspect and mitigate culture's impact through its universal appeal.

- Integrated studies: to bring all the constructs together into a solution framework

3. Third stage: identifying the parts of the industry

At this stage, the construction industry is treated as a system of systems. Therefore, it is essential to identify its parts, its systems, or its organisations. The idea is that the industry's development should be seen as an emergent state resulting from the aggregation of its parts' development.

4. Fourth stage: developing the conceptual framework and the maturity framework

At this stage, the relevant constructs of the study have been identified in (1), (2), and (3). The next activity was to model the constructs so identified in the study into a conceptual framework and a maturity framework which address the main research problem. At this stage, the constructs are developed into a measurable form and, therefore, become variables.

\subsection{Limitations}

In this study, some limitations were identified. Firstly, the literature materials selected considered only those in English. Scientific works published in other languages that were inevitably disregarded may have increased the study's arguments' strength. Secondly, because the scope of the topics involved in sustainability and construction industry development is quite broad, the study could not have covered all that may have been relevant. Those materials disregarded for a qualitative sampling of literature may have provided some critical dimensions to the study.

Further, this paper's focus means that other construction industry development indicators were excluded, namely, the industry's GDP and site productivity issues. Finally, despite its contribution to knowledge, the proposed framework has not gone through the complete cycle of being launched for performance assessment and evaluation. Therefore, it has been submitted as a conceptualised model or a theoretical framework ready to be tested, verified, 


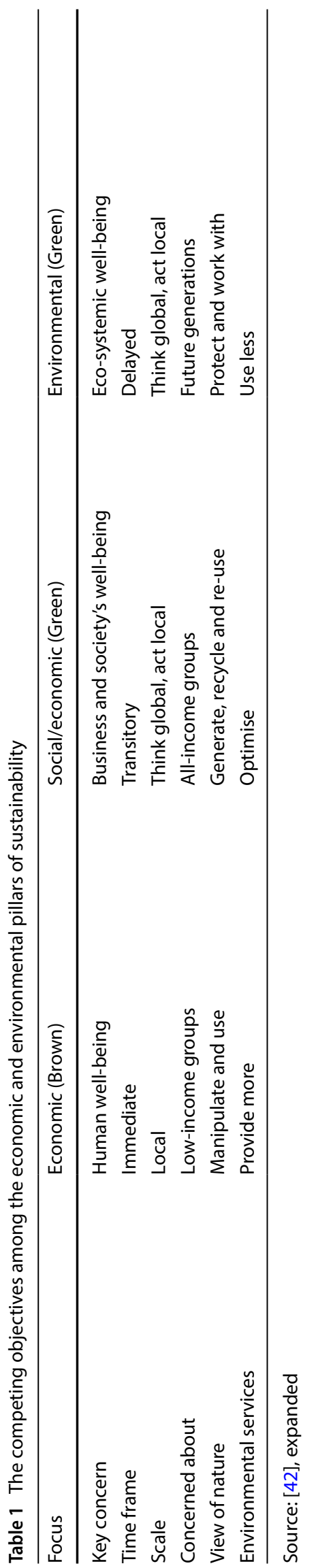


and validated. However, the methodological approach adopted and the features of the proposed framework are such that it shows promise of a theoretical construct and the capacity of instigating further studies.

\section{Results and discussion}

This section contains the results that emanated from the literature review methodology. The main issues discussed were sustainable development and system thinking as a crucial part of a framework for studying construction industry development. In the process, the components of construction industry development were identified. Also, the key stakeholders in the industry were identified. These findings formed the basis for modelling (1) a conceptual framework for the study and (2) a proposed framework for measuring the maturity level of the construction industry in its path towards development.

\subsection{Construction industry development: a systemic and sustainable view}

Apart from the fundamental challenges inherent in the industry, approaches used by countries to develop the industry also need to be investigated. This investigation is vital because attempts at developing the industry towards efficiency must necessarily include principles and strategies needed to address the challenges emanating from its nature, processes, and practices. Firstly, it will require identifying all the relevant components of construction industry development, all the organisations that make the construction industry, all the external environmental factors that impact the industry's growth or otherwise, and the project as a special (temporary) organisation. Secondly, it will require the need to know what to do to ensure that they contribute to its development. A well-structured approach to overcoming the challenges is the surest way of successful development. Thus, there is the need for a holistic (systemic) approach towards the industry's development. Therefore, systems thinking and systems engineering philosophies must be the governing paradigm for such approaches. The approach is to view the entire construction industry as a system, or more succinctly, a system of systems. Within the parlance of systems engineering, the construction industry must be seen as a system of several different subsystems. Therefore, its development must focus on the development of its systems. Sustainable construction is the subject of discussion in this sub-section.

\subsubsection{Sustainable construction}

The Cls development should be based on the development and the sustainability of its core activity: construction. The construction industry must exist to deliver today and continue to do the same in the future so long as shelter and transportation infrastructure continue to be relevant to human existence. Regarded as an industry that consumes a large percentage of the world's natural resources, the fear of the long-term negative impact on the environment led to the need to consider sustainable construction within the broader concept of sustainable development [37]. Sustainable construction has been spearheaded by Kibert [38], Du Plessis et al., and Du Plessis [39, 40]. In several countries, attempts are being made to focus on the six principles of sustainable construction as contained in Agenda 21 [37]: (1) Minimisation of resource consumption, (2) maximisation of resource re-use, (3) use of renewable and recyclable resources, (4) protect the natural environment, (5) create a healthy and non-toxic environment, and (6) pursue quality in creating the built environment. Ultimately, sustainable construction must, of necessity, be linked with the developmental agenda of the industry.

\subsubsection{Sustainable construction and the conflict between the triple bottom line}

The Earth's capacity to regenerate itself is affected directly by society, the environment, and the economy (also known as "people", "planet", and "profit", respectively) [41]. It is also referred to as the triple bottom line (TBL) adopted for this paper. As the Brundtland report suggests, only when the requirements of all the three complementary forces are balanced will sustainability be genuinely achieved. Sustainable construction demands that all three areas should be given equal and important attention. Further to this, the "Russian Doll and Five Capital Model" shows that economic activity is centrally placed and is constrained by social issues, which in turn are constrained by environmental factors [41].

It is essential to show the existence of an inextricable link and competing interest among the TBL. As an illustration, it is significant to know that they have different objective to pursue, and they sometimes contend with one another. For example, the dichotomy is evident between the quest for economic growth (brown) and that of environmental protection (green) [42]. The former aims at consumption, while the latter focuses on protection. The factors that promote the 


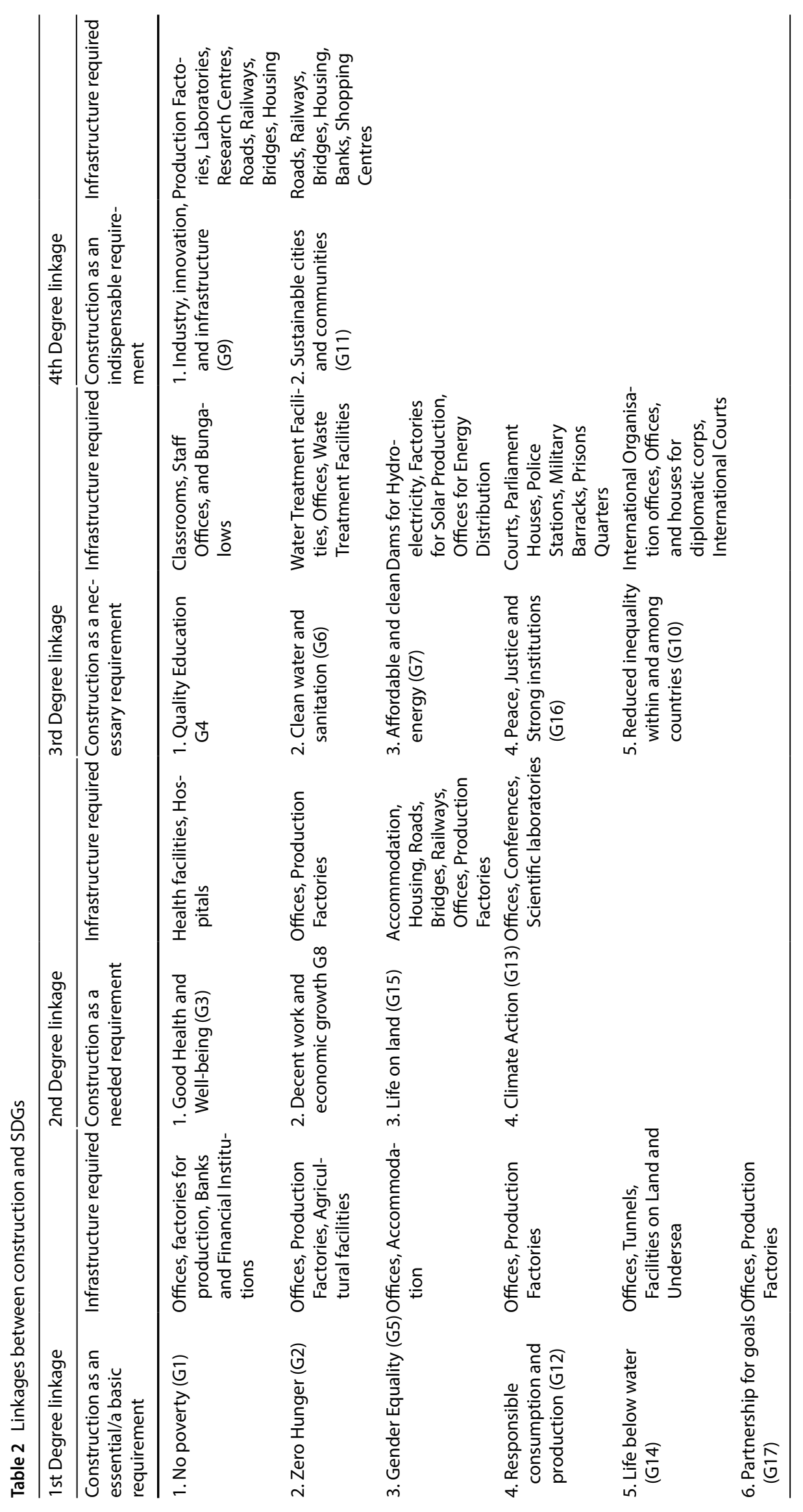


Table 3 Stakeholders (organisations) in the construction industry [48]

\begin{tabular}{ll}
\hline Stakeholder Roles and responsibilities & Ror
\end{tabular}

National and local policy-makers

Clients, public and private

Consultants for design, supervision, and other functions

Contractors main and subcontractors

Suppliers

Banks, insurance companies, and private investment funds

International partners and donors

Regulatory and standard-setting bodies

Legal service providers

Auditors

Professional associations

Trade unions

Tertiary education institutions
Policy- and decision-makers at the national and local level are essential in establishing the enabling environment for the construction industry's development and promoting the type and volume of public infrastructure to be provided. Close cooperation between the private sector and policy-makers is thus essential

Clients identify needs and initiate works, procure consultants and contractors for the design, execution, and supervision of works, and monitor and payment service providers. For infrastructure works, the main clients are relevant sector ministries at various levels and local authorities

Engineering consultants conduct studies (such as feasibility, social and environmental safeguard studies, geological and hydrological surveys), design infrastructure, prepare cost estimates, prepare contract tenders, and supervise contractors' works

Contractors execute infrastructure works and supply the necessary resources (labour, tools, equipment, and materials). Depending on the type of contract, the work being done by contractors may be supervised by consulting engineers. Relatedly, the main contractor may sublet some of the works to smaller or specialised firms called subcontractors

Suppliers are often specialised firms selling construction materials, tools and equipment-and spare parts. Suppliers are expected to offer and sell safe and sound quality goods

Bank and insurance companies provide financial services, including loans, performance bonds, and guarantees. They also provide financing for infrastructure works and play a significant part in contractors' development and operations

Includes bilateral and multilateral development partners that provide finance and support services, e.g., technical assistance, research

Regulatory and standard bodies may be governmental or private institutions, which may operate nationally or internationally. Their primary function is to develop and maintain product specification standards, process standards, and behavioural standards, e.g., anticorruption, corporate social responsibility

The services of lawyers and other legal persons may be required for all types of legal matters but mainly about procurement regulations, conditions of contract, disputes, and auditing

Internal and external auditors carry out technical and financial checks of infrastructure works during and after implementation. These checks are necessary to assure the client and the public that the work is being carried out following specified norms and standards and within budget

Associations play an essential role in the construction sector, both for contractors and engineers. Their central role is to promote their members' interests, develop industry standards, and provide support services (e.g., training, advice, promotion), and lobby for works

Trade unions protect workers' rights and promote their common interests in the fairness of pay, safe working environments, hours of work, benefits

Universities and other higher learning institutions provide the construction industry with the required professionals. It is their responsibility to closely cooperate with the construction sector partners to formulate and implement appropriate educational programmes, both theoretical- and practice-oriented 
Table 3 (continued)

\begin{tabular}{ll}
\hline Stakeholder & Roles and responsibilities \\
\hline Vocational education and training institutions & $\begin{array}{c}\text { Vocational training is essential to secure an adequate supply of com- } \\
\text { petent and skilled artisans and technicians. They are the backbone } \\
\text { of the construction industry, and thus vocational education insti- } \\
\text { tutes must collaborate closely with the industry and its professional } \\
\text { associations }\end{array}$ \\
\hline Communities & $\begin{array}{l}\text { Communities are the ultimate users and beneficiaries of public infra- } \\
\text { structure. They should be empowered to participate in the entire } \\
\text { programme cycle from identification to infrastructure assets' final } \\
\text { commissioning and operation }\end{array}$ \\
\end{tabular}

former's accomplishment appear to increase those factors that work against the latter. However, for purposes of sustainability, the concept of "green economy" must be invoked, where a green economy is defined as: "an economy in which economic growth and environmental responsibility to work together in a mutually reinforcing fashion while supporting progress on social development" [43]. McGranahan and Satterthwaite's views [42] as expanded to include the expected green social/economic aspect are depicted in Table 12 . Bringing in the social dimension will undoubtedly increase the complexity of the problem due to the need for a trade-off between people's comfort and survival today under green economic and environmental conditions. It is against the backdrop of what is needed to satisfy society's unquenchable appetite to consume.

However, the ultimate constraint is the Earth's ecosystem, which must always be given the needed attention, which is the central goal of sustainability. Being a significant consumer of natural resources, focusing on the earth ecosystem will directly impact construction. The extent to which construction activities consume natural resources makes it an essential ally in the quest for sustainable development. All these go to show that the concept of sustainability is a rather complex subject [40]. Fusing it within the complex construction setting will inevitably create conditions that will underscore the challenges that need to be overcome to accomplish the industry's developmental goals.

In Table 12 , a comparison is made among the triple bottom line in the light of six focus criteria:

key concern, time frame, scale, concerned about, view of nature, environmental services. In its original state, it was designed for a comparison between the environmental and the economic pillars. The authors introduced the social pillars to have a holistic view of the contention among the three. It could be seen that the social pillar fits nicely between the environmental and the economic pillars as a moderator between the two apparent extremes. It means that society is being seen as the reason for the struggle between the brown and the green. That is, society becomes the winner or the loser based on the result of the original conflict. Therefore, there can only be a green economy if society supports it. The table shows that there is always a link between the social and the economic pillars; it is a matter of survival. Thus, society's primary work will be to support the environmental course and support the green economy. This discussion shows the interplay of issues that must influence the three in sustainable construction industry development activities.

\subsubsection{Aligning the goals of $\mathrm{Cl}$ activities with the SDGs}

Specifically, only two of the seventeen goals, i.e., goals 9 and 11, relate to construction activities. However, a critical study of the other SDGs shows that each has something to do with construction and depends on its accomplishments in varying degrees. Table 23 shows the dependence of the SDGs on construction or a constructed facility. In the table, the SDGs' linkages with construction have been established at varying levels of dependency. These are from the level of an essential/ a basic requirement through a needed requirement, a necessary requirement, and an indispensable requirement. Thus, the primary consideration is that every step towards sustainability in the construction industry should have at least one SDGs to accomplish.

\subsubsection{Employing system thinking to sustainable development}

The $\mathrm{Cl}$ is too fragmented, interconnected, and complex to be developed sustainably without considering its systemic nature. The various parts of the $\mathrm{Cl}$ system must be seen to depend on each other, support each other and move together as a system. According to UNESCO [44], it is not enough to depend on technology, politics, and financial consideration 


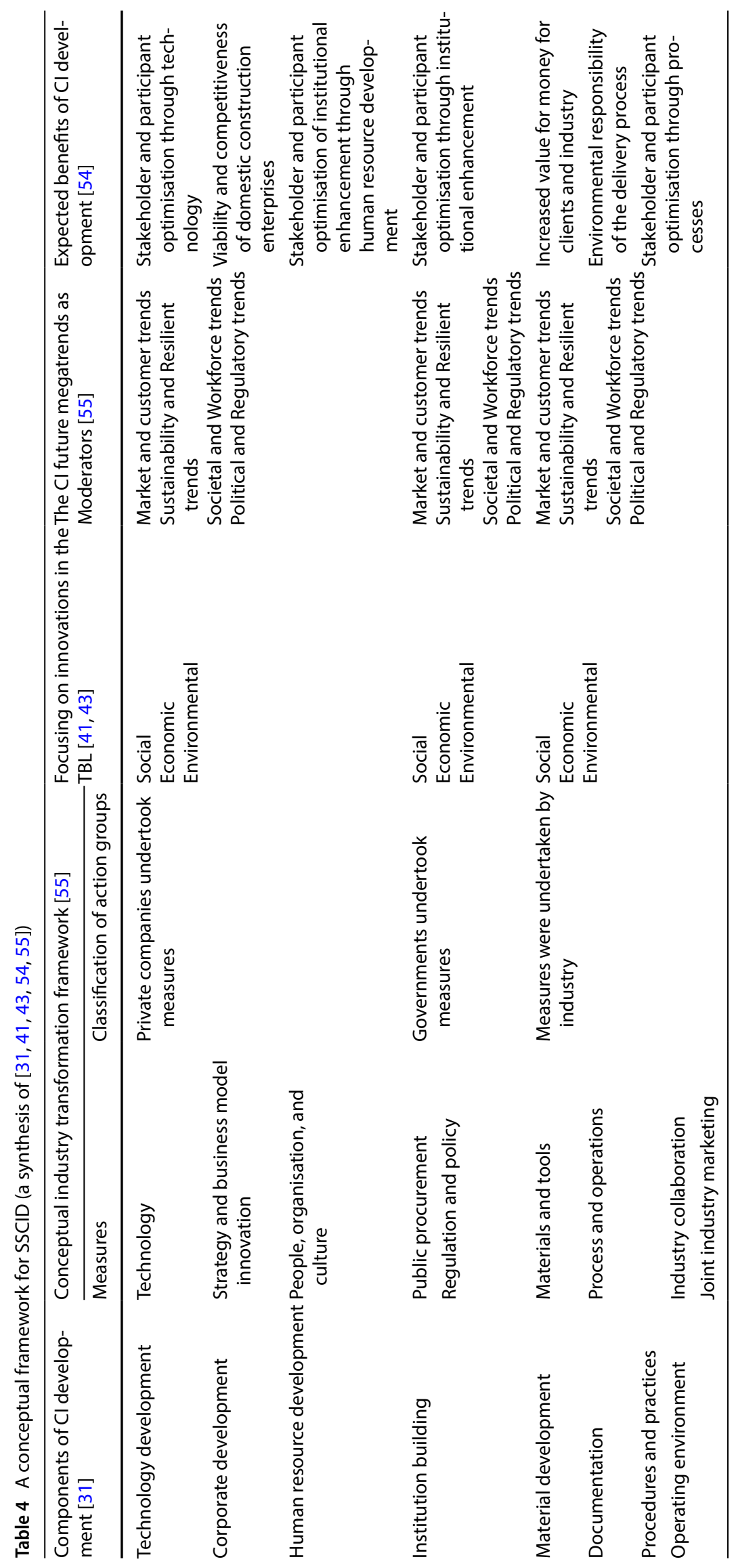


when pursuing sustainable development goals. Thus, a holistic methodology that will support a resilient system and flexible structures to take care of complexity is recommended [45]. Draper [46] has said that systems thinking is understood as the ability to see the world as a complex system where everything is connected to everything else. In light of these, this paper posits a deficiency in theory and practice and counterproductive for different groups to pursue a common agenda such as sustainable development in their separate and different self-contained environments. It is even worse when this persists without any attempt to link them to consider the whole picture. The issues involved in achieving sustainable development require a holistic consideration of all the items concerned. According to Ison [47], integrating the parts into making it a whole is necessary for a system to exist. This integration should result in a special relationship between the parts with essential emergent properties. Within the $\mathrm{Cl}$, systems are organisations and firms operating to define the $\mathrm{Cl}$ as a system of systems. These include clients, contractors, consultants, suppliers (Table 34 ) [48] and even projects as temporary organisations [49]. System thinking has been seen as an invaluable tool in addressing complex problems of sustainable development. Cloud [50] has said:"system dynamics and systems thinking can be taught without involving sustainability, but sustainability cannot be taught without involving systems thinking". Systems can be defined as elements joined together by dynamics that produce an effect, create a whole or influence other elements of a system. For this reason, systems thinking, and indeed, systems engineering are fundamental approaches recommended for any studies on sustainable construction within the industry's development agenda.

\subsubsection{System engineering}

Checkland [51] identified three types of systems engineering as follows:

i. Product systems engineering (PSE): this is traditional systems engineering focused on designing physical systems consisting of hardware and software.

ii. Enterprise systems engineering (ESE): this view of enterprises as systems, organisations, or combinations of organisations.

iii. Service systems engineering (SSE): this is about the engineering of service systems.

The construction industry system takes after the enterprise systems engineering. ISO/IEC/IEEE 21839 [52] defines a system of systems (SoS) and the constituent System as follows:

System of Systems (SoS): set of systems or system elements that interact to provide a unique capability that none of the constituent systems can accomplish independently. Systems elements can be necessary to facilitate the interaction of the constituent systems in the System of systems.

Constituent Systems: constituent systems can be part of one or more SoS. Each constituent is a useful system by itself, having its development, management goals, and resources, but interacts within the SoS to provide the unique capability of the SoS.

These are the organisations, enterprises, and projects within the larger construction industry system of systems as listed in Table 4. The standard indicates that the formation of an SoS is not necessarily a permanent phenomenon but rather a matter of necessity for integrating and networking systems in a coordinated way for specific goals such as robustness, cost, and efficiency. Because each constituent systems (organisations) are independent, these development processes are implemented for engineering both the systems and the System of systems. They need to be tailored to support the characteristics of SOS (refer to ISO/IEC/IEEE 15288 Annex G). Indeed, the construction industry's existent as a temporary phenomenon encapsulates it entirely as a system of systems.

\subsection{Identifying the components of the $\mathrm{Cl}$ development}

Construction industry development has always been considered hinging on a deliberate process undertaken under well-managed conditions [53,54]. Such a venture's benefits include increased value for money, the competitiveness of construction enterprises, and the optimisation of stakeholders' performance [50]. It brings to the fore the need to consider the industry's needed aspects to focus on as very important to the development agenda. Ofori [31] identified what he referred to as the components of construction industry development: technology development, corporate development, institution building, material development, human resource development, documentation, procedures and practices, 


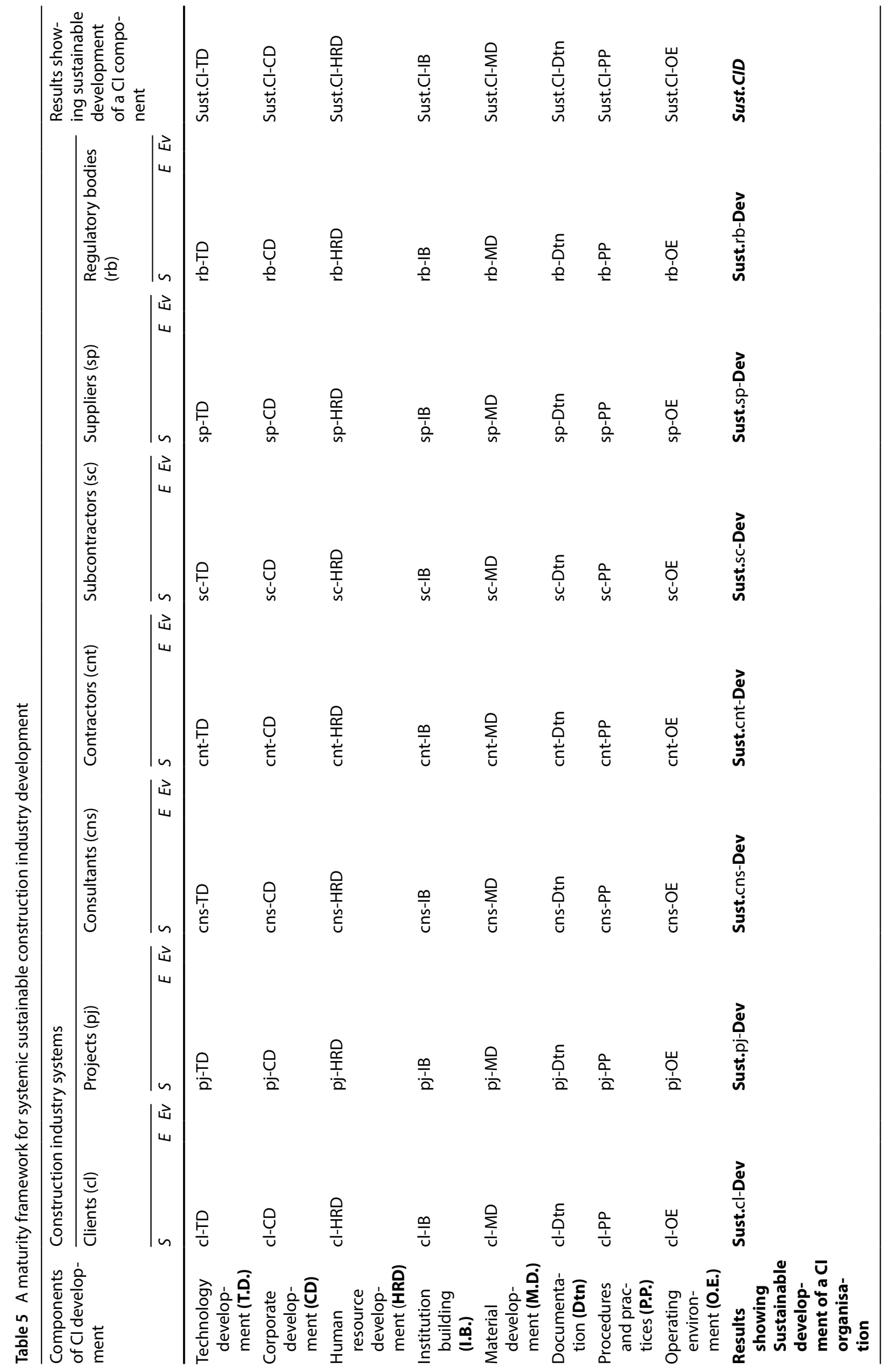




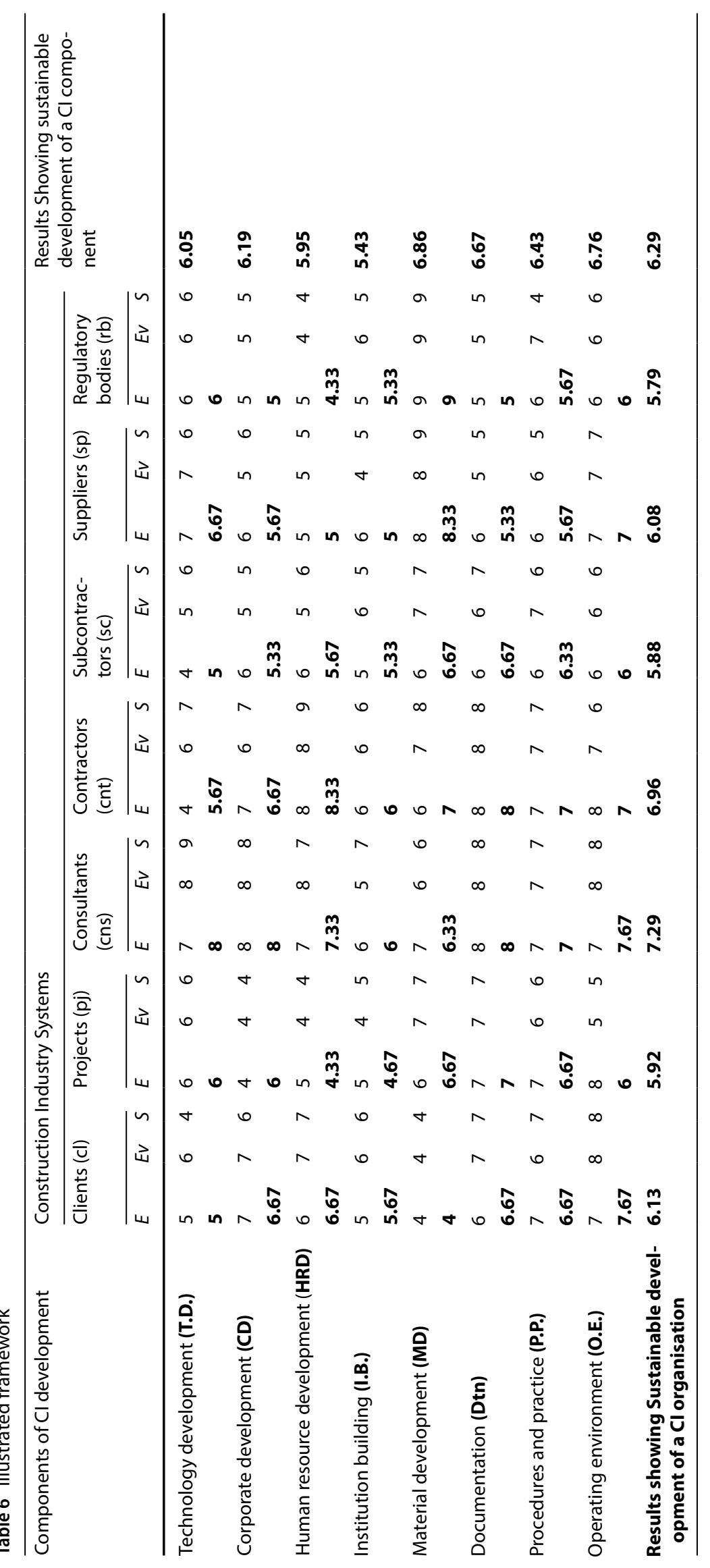


and operating environment. The position is that the development of the components will aggregate to represent that of the entire industry. These are issues that relate to the various organisations or enterprises within the industry.

In a related discussion, the present state of construction industries and the global trends that will impact the industry was assessed by the World Economic Forum (WEF) [55]. A primary deliverable from the assessment was a conceptual industry-transformation framework that listed several measures. These measures were grouped into eight topical areas: (a) technology material and tools (b) processes and operations (c) strategy and business model innovation (d) people, organisation and culture (e) industry collaboration (f) joint industry marketing (g) regulation and policies and (h) public procurement. The similarities between these measures and Ofori's [31] are striking. These were further classified into three categories as (i) measures taken by private companies on their own; (ii) measures taken by companies in collaborations with their peers-or by the industry as a whole; and (iii) measures taken by the government, acting both as the regulator, and as a significant project sponsor. According to the report, the future transformation of the $\mathrm{Cl}$ would be shaped by (a) market and customer trends, (b) sustainability and resilient trends, (c) societal and workforce trends, and finally, (d) political and regulatory trends. Together, the Ofori [31] model and the WEF [55] frameworks are considered to be well-positioned to address the challenges militating against the performance, growth, and deliberate development of the construction industry.

The international chamber of commerce [43] provided a green economy roadmap focusing on ten interdependencies distributed across the TBL with mutually reinforcing and cross-cutting elements at the centre as follows: (1) Economic Innovation: open competitive market, metric accounting and reporting, finance and investment. (2) Environmental Innovation: life cycle approach, resource efficiency and decoupling (3) Social Innovation: awareness, employment, education, and skills (4) Mutually reinforcing and cross-cutting elements (from the three): governance and partnership, integrated policy, and decision-making.

It is essential to look at Ofori [31] and WEF [55] in the light of the green economic framework along with its roadmap [43] completely. It is expected that this would profoundly change the industry as a system and lead it towards the path of sustainable growth. Given the construction industry's societal, environmental, and economic importance, it is expected that any performance improvement in the industry will also have a substantial effect on all three domains in different forms and degrees.

\subsection{A conceptual framework for SSCID}

Based on the preceding, a conceptual framework is modelled based on a synthesis of Tables 1 and 3 , the components of $\mathrm{Cl}$ developement, and the industry-transformation framework (as identified above) to achieve the following purposes (Table 4 1):

1. Indicate the delineating of all the critical components of $\mathrm{Cl}$ development.

2. The classification of the action points.

3. The future Megatrends in the $\mathrm{Cl}$.

4. The links with the triple-bottom-line in sustainability.

5. The expected benefits for the $\mathrm{Cl}$.

In Table 4 1, the first two columns show how the components of $\mathrm{Cl}$ development are aligned with the measures of the conceptual industry-transformation framework. The Table also shows the position of the green economy roadmap within the framework. It is essential to note the similarity and how the two sets of items reinforce each other. In transforming the $\mathrm{Cl}$, these components are the key areas to look at and develop. This synthesis made it possible to classify these components into three groups of action points to be prosecuted by the three action groups: private companies, the government, and the industry. They form the main framework by which the $\mathrm{Cl}$ development process should be structured and managed. Column four shows the aspect of sustainability and the TBL innovations. This aspect is crucial to the development of organisations (stakeholders) in the industry. Column five shows the four megatrends that will shape these developments, acting as moderators of the process. Cl system developers must closely monitor these trends and continuously manage the components appropriately. The $\mathrm{Cl}$ areas that stand to benefit directly from these components' developments are listed in column six. These were initially outlined by Ofori [54]. This framework contains what is needed for addressing the inherent challenges of the $\mathrm{Cl}$. Table 41 also provides the foundation upon which the proposed maturity framework was developed (Tables 5, 6). 


\subsection{The organisations (systems) in the construction industry}

Table 3 is a list of all the stakeholders making the construction industry. These stakeholders are the organisations in the industry. Considering the construction industry as a system of systems, these become the systems in the industrial systems. The industry's development also means that each organisation needs to be developed in the eight components. Only when these systems are deliberately being developed individually in these eight components and within the TBL can one say that the industry is being developed. The extent of each of the systems' development should be measured, monitored, and managed towards the desirable level. The aggregation of all the systems' development will represent the industry's development at a point in time.

\section{A proposed framework for assessing the maturity level of SSCID}

Based on Tables 3and 4, Table 5 is designed. Table 5 is a proposed framework that could guide the assessment of the typical construction industry's maturity levels. The process involves considering a $\mathrm{Cl}$ system of systems that must capture all the relevant systems (organisations): clients, consultants, and contractors, among others, as identifiable and relevant for a specific construction industry [48]. These are made to develop along the eight (8) identified components of $\mathrm{Cl}$ development [31]. These are (1) Technology Development (TD), (2) Corporate Development (CD), (3) Human Resource Development (HRD), (4) Institution Building (IB), (5) Material Development (6) Documentation (Dtn), (7) Procedures and Practice (PP), (8) Operating Environment (OE). For each System or organisation, the focus is to ensure a component-by-component development taking into consideration the Social (S), Economic (E), and Environmental (Ev.) dimensions [36, 42].

The working process of the framework is designed to answer the following questions towards sustainable development:

1. To what extent is each of the organisations in the industry maturing through each of the eight components?

2. To what extent the components developed in compliance with sustainability measured through the TBL in each organisation?

3. To what extent is the industry developing?

\subsection{Towards mathematical validity of the framework (Table 6)}

Table 6 is a simulation of the proposed framework in operation with numerical figures. The values used to illustrate how the framework could be used in actual assessment when accurate data are obtained from a field study. With this as a basis, this section illustrates how the maturity levels of (1) the systems and (2) the components, and (3) the $\mathrm{Cl}$ are assessed.

1. The scores under the TBL

In Table 6, the values inserted into the columns represent scores obtained when each of the $\mathrm{Cl}$ organisations (systems) are assessed across the various components in turn in the light of sustainability through the TBL. The measures are scored over ten marks. These are then averaged to represent the organisation's sustainable development (It could also be measured in percentages). The overall score is the average values across the three pillars as follows:

$$
\text { Average Scores }=1 / 3[\mathrm{E}+\mathrm{Ev}+\mathrm{S}] \text {. }
$$

This figure shows the maturity level of a component under organisation within the industry.

It must be noted that each score is an industrywide average brought to the framework as the final scoreboard. The framework is the final scoreboard after all the figures are obtained by field assessment.

In Table 6, the maturity level of sustainable development of Technology Development under the clients' organisations obtained, taking cognisance of the TBLs, are E (5), Ev. (6), and S (4). The average is, therefore, $(5+6+4) / 3=5$.

2. Measuring the maturity level of a component in the construction industry $[\mathrm{MC}]$

Similarly, the maturity level of the Technology Development component scored under each of the systems is:

Projects (6), Consultants (8), Contractors (5.67), Subcontractors (5), Suppliers (6.67), and Regulatory Bodies (6).

Thus, for a component under the seven systems (organisations), we use the formula:

$$
\mathrm{MC}=1 / 7[\text { Clients }+ \text { Projects }+ \text { Consultants }+ \text { Contractors }+ \text { Subcontractors + Suppliers + Regulatory Bodies }] \text {. }
$$




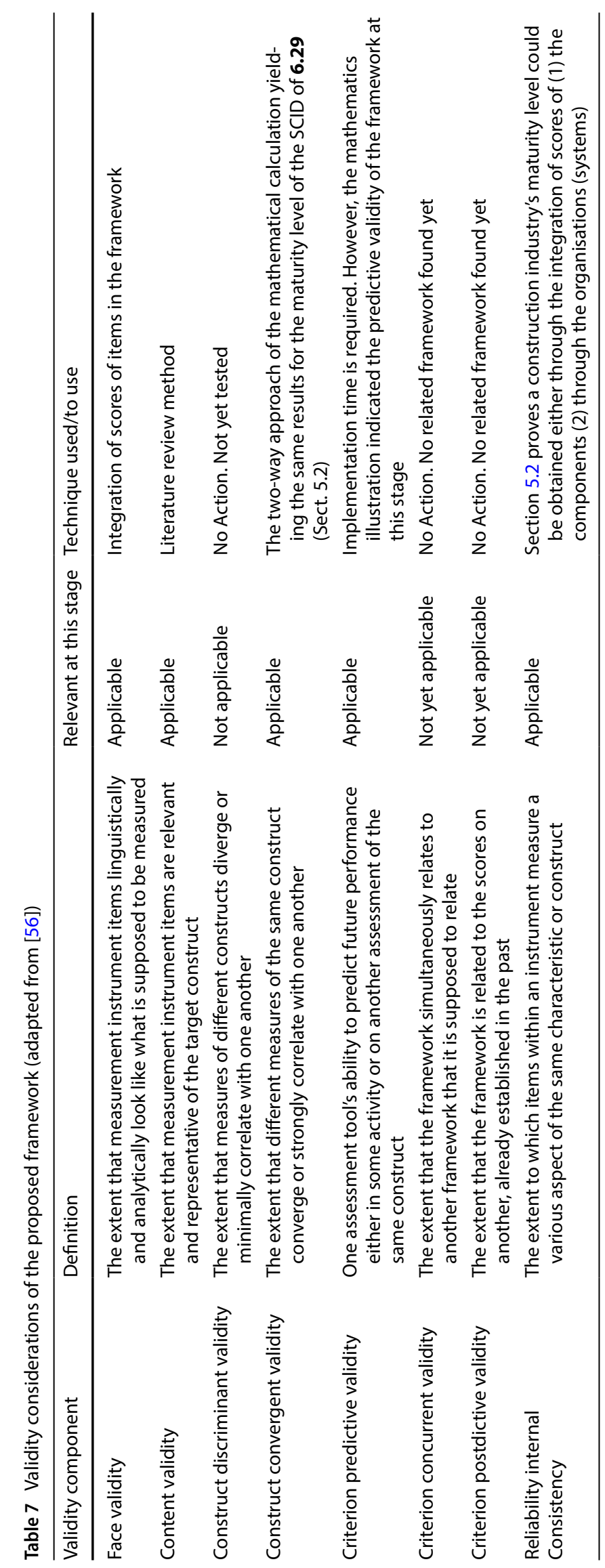


For seven organisations (or systems) in focus.

Thus, concerning Technology Development, we have:

$$
1 / 7[(5)+(6)+(8)+(5.67)+(5)+(6.67)+(6)]=\mathbf{6 . 0 5} .
$$

The average score obtained under all the systems of the industry. This result is the maturity level of Sustainable Technology Development in the Cl. If all the organisation's particular construction industry organisations are considered.

3. Measuring the maturity level of system in the industry [MS]

The formular for assessing maturity level of a system in the industry is measured along all the components as:

$$
\mathrm{MS}=1 / 8[\mathrm{TD}+\mathrm{CD}+\mathrm{HRD}+\mathrm{IB}+\mathrm{MD}+\mathrm{Dtn}+\mathrm{PP}+\mathrm{OE}] .
$$

Using the columns (vertical) assessment for each group of organisations, e.g., the clients' organisations (systems) along all the eight components, we have:

$$
1 / 8[\mathrm{TD}(5)+\mathrm{CD}(6.67)+\mathrm{HRD}(6.67)+\mathrm{IB}(5.67)+\mathrm{MD}(4)+\mathrm{Dtn}(6.67)+\mathrm{PP}(6.67)+\mathrm{OE}(7.67)]=\mathbf{6 . 1 3}
$$

The result is 6.13, representing the maturity level of Sustainable Development of Clients' Organisations in the construction industry.

This process is repeated for all the other organisations or systems within the industry.

4. Measuring the maturity level of a sustainable construction industry overall $[\mathrm{MCl}]$

The formula is given as:

$$
\mathrm{MCI}=\sum_{\mathrm{k}=1}^{8}(\mathbf{M C})=\sum_{\mathrm{k}=1}^{7}(\mathbf{M S}),
$$

where $\sum_{\mathbf{k}=1}^{8}$ (MC) represent the aggregation of the maturity levels of all components in the industry across the seven systems; and, $\sum_{\mathrm{k}=1}^{7}(\mathbf{M S})$ represents the aggregation of the maturity levels of all the systems in the construction industry across the eight components.

Each of the above summations will yield the same value representing the maturity level of sustainable construction industry development. From Table 6, the overall maturity level of sustainable construction industry development is 6.29, using either of the two formulae.

\subsection{The classification of the maturity levels}

For purposes of this paper, the maturity levels are classified as follows:

1. $1-1.99=$ Level 1

2. $2-2.99=$ Level 2

3. $3-3.99=$ Level 3

4. $4-4.99=$ Level 4

5. $5-5.99=$ Level 5

6. $6-6.99=$ Level 6

7. $7-7.99=$ Level 7

8. $8-8.99=$ Level 8

9. $9-9.99=$ Level 9

10. $10=$ Level 10 .

Level 1 is the least matured level, while Level 10 stands for the most matured level. Thus, using $x=$ score for a maturity level, we have $1 \leq x \leq 10$.

For any score, " $x$ ", which falls between $x .00 \leq x<x .50$, the level is qualified by "Low". Therefore, scores like 1.43, 5.32, 7.22 are classified as 1-Low, 5-Low, and 7-Low, respectively.

Similarly, for any score " $x$ ", where $x .50 \leq x<x+1$, the level is qualified by "High". Therefore, scores like 1.54, 5.66, 7.51 are classified as 1-High, 5-High, and 7-High, respectively. Thus, the result of the Sust.CID $=6.29$ means the industry in question is at the level of 6-Low. 


\subsection{Monitoring and managing the $\mathrm{Cl}$ development}

Table 6 has indicated the process of measuring the maturity levels of the various aspect of the industry. The values so obtained indicate the general position of a particular industry. When this is done at regular intervals, it will provide a means by which the maturity level can be monitored through trend analysis of these figures. Based on these scores, deliberate action should be taken to manage the industry to the desired level.

It means that targets will have to be set, and the levels achieved should indicate deviation, which must be corrected and identified gaps filled. This approach should be seen as the scientific way an industry's transformation, growth, and development can be achieved.

\subsection{Pre-requisites}

Some pre-requisites should be agreed on before the framework could be used. The framework comprises main measures in three dimensions: (1) the components of the industry development, (2) the systems or organisations in the industry, and (3) the TBL. There should be agreement on the set of indicators needed to assess each of the primary measures. This process will be the basis for populating the main measures that will aggregate into the organisations' maturity level or systems and, ultimately, the construction industry. These indicators may then be adapted to suit each country's needs. Methods for measurement and compilation of the indicators should also be agreed on to facilitate standardisation and adaptation. At this stage, the framework is being proposed for predicting maturity. It is expected that it could also be a framework for benchmarking and inter-industry comparison after some modification.

A central agency will be needed to administer the construction industry development programme using the proposed framework. The duty of such an agency would be to collect, process, and disseminate critical data on the construction industry and maintain a national construction database for estimating the scores of the indicators. These data need to be updated regularly to meet the industry's current trends and needs and knowledge development. The ultimate objective shall be to regularly measure and monitor the industry's maturity level, predict growth, development, or decline for decision-making and management by the government pursuing a construction industry development agenda.

\subsection{Towards the validity of the framework}

The proposed framework was subjected to some fundamental validity and reliability tests as far as practicable, and the results are summarised in Table 7. The following provides a background to the contents of Table 7.

1. Literature review method

Because the framework's variables emanated from empirical studies, it is concluded that their validity and reliability as measures have been established. However, using them to model a framework means that the framework needs to pass the validity and reliability tests. Later, the framework's actual implementation will represent its validation and the testing of the theory it propounds. The issue of validation of the framework is beyond the scope of this paper.

2. By using numerical simulation where the numerical methods solve the System

In this paper, basic numerical simulation has been used to validate the mathematics underlying the framework's measurement aspect. Integrating the scores into the maturity level has been triangulated by estimating from either the systems' side or the component's side. The results have been consistent.

3. Monte Carlo simulations proposed for experimental validation

During the actual validation of the framework, multiple results obtained from the experiments could be further validated by Monte Carlo simulations, primarily as it assesses the industry's maturity levels and predicts their expected behaviour and growth. The reason is that Monte Carle-based predictions of failure or success have been proven to be routinely reliable. 


\title{
6 Conclusion
}

The study has shown that the issues involved in construction industry development are a more complex problem than has hitherto been considered. It has revealed that a systemic approach is needed to achieve the development agenda. Further, it has also shown that the industry's development should be considered with sustainability in mind and that the two must go together. Thus, the agenda should be sustainable construction industry development. Also, this study propounds that sustainable construction industry development should be seen as part of the global agenda of a sustainable world as it began with Agenda 21 and the SDGs. The significance of this is that construction is linked to all the seventeen SDGs in four varying degrees: as an essential requirement, as a needed requirement, as a requirement, and as an indispensable requirement for their accomplishments. At the heart of sustainable construction, a debate is the need to ensure the TBL in all cases. Decisions will have to be made in light of possible trade-offs between and among the SDGs and The TBLs.

Due to its complexity, interconnectedness, and fragmentation, integration became paramount among what to do to accomplish true transformation and development. A holistic consideration of the industry is necessary. It brings to the fore the need for systems thinking. The $\mathrm{Cl}$ is considered part of a larger, more complex global system. Also, it is considered as a system that comprises various construction systems. As a system of systems, the systems of systems were introduced to place the industry in good stead towards its systemic development. Thus, to develop the construction industry, it is crucial to focus on developing the subsystems. The reason is that the industry's subsystems can develop on their own regardless of their individual needs and goals. They must interact within the SoS to provide its emergent behaviour. Thus, they must be engineered as a deliberate action towards the desired direction of development.

In all clarity, construction industry development should be seen as a continuous process of deliberately ensuring that a holistic approach is adopted to achieve the industry's transformational goals, considering the concept of sustainability. Thus, the researchers contributing to the debate must consider, alongside the approaches towards achieving sustainable construction goals through its subsystems, the impacts, attractions, disruptions, and distractions from other industries or systems. Thus, the ultimate goal of systemic, sustainable construction industry development (SSCID).

Based on the preceding, it was possible to design a framework by which the maturity level of the construction industry could be assessed in the light of the eight components, the TBL, and the organisations within the industry. Even though the framework is submitted as a theory to be tested, the mathematics proves that there is the potential it as a support system in the quest for systemic, sustainable construction industry development.

The study's significant contribution to knowledge is that it has demonstrated a measurement approach to the development agenda. The lack of it has been one of the weaknesses in the construction industry development programmes. This study implies that there is a need to have an expanded view of the construction industry. The study's outcome also implies that countries' construction industry development programmes should be well-structured, carefully balanced under TBL conditions, and systemically prosecuted.

\begin{abstract}
Authors' contributions The corresponding author is the lead author. The contributing authors performed the following functions: 1. Helped in the revision of certain sections of the document. 2. Reviewed Tables 1 and 4. 3. Proof-read the entire document. 4. All authors reviewed the manuscript. All authors read and approved the final manuscript.
\end{abstract}

\section{Declarations}

Competing interest The authors declare no competing interests.

Open Access This article is licensed under a Creative Commons Attribution 4.0 International License, which permits use, sharing, adaptation, distribution and reproduction in any medium or format, as long as you give appropriate credit to the original author(s) and the source, provide a link to the Creative Commons licence, and indicate if changes were made. The images or other third party material in this article are included in the article's Creative Commons licence, unless indicated otherwise in a credit line to the material. If material is not included in the article's Creative Commons licence and your intended use is not permitted by statutory regulation or exceeds the permitted use, you will need to obtain permission directly from the copyright holder. To view a copy of this licence, visit http://creativecommons.org/licenses/by/4.0/. 


\section{References}

1. Ofori G. Challenges of construction industries in developing countries: lessons from various countries. Conference Paper, Challenges Facing Construction Industries in Developing Countries. In: 2nd International Conference on Construction in Developing Countries: Challenges facing the construction industry in developing countries 15-17 November. Gabarone, Botswana. 2000.

2. Ofori G. Indicators for measuring construction industry development in developing countries. Build Res Inform. 2001;29(1):40-50.

3. Gyadu-Asiedu, W. Assessing construction project performance in Ghana: modelling practitioners' and clients' performance. A PhD. Dissertation submitted at the Technology University of Eindhoven (TU/e), The Netherlands, 2009.

4. Makulwasaatudom A, Emsley M, Sinthawanarong K. Critical factors influencing construction productivity in Thailand. In: Second International Conference on Construction in the 21st Century (CITC-II) "Sustainability and Innovation in Management and Technology", 10-12 December, Hong Kong. 2003.

5. Chimwaso DK. An evaluation of cost performance of public project case of botswana. conference proceedings, construction industry development in the new millennium. In: 2nd International Conference on Construction Industry Development and 1st Conference of CIB TG 29 on Construction in Developing Countries, Singapore. 2000.

6. Zhang Y, Zhang Y, Zhang L. Study on reasons for delays in civil engineering project in China. In: Conference Proceeding, "Sustainability and Innovation in Management and Technology", 10-12 November 2003, Hong Kong. 2003.

7. Le-Hoai L, Lee YD, Lee JY. Delay and cost overruns in vietnam large construction projects: a comparison with other selected countries. KSCE J Civil Eng. 2008;12(6):367-77.

8. Windapo AO, Cartel K. The South African construction industry: perceptions of key challenges facing its performance, development and growth. J Constr Dev Countries. 2013;18(2):65-79.

9. Naoum S, Dejahang F, Fong D. A new Framework for determining productivity factors on construction sites. In: CIB Joint International Symposium 2009 Construction Facing Worldwide Challenges. Dubrovnik, September, 27-30. 2009. pp. 109-121.

10. Tijhuis W. Crisis or challenge? Thought about international construction industry recovery strategies. In: CIB Joint International Symposium 2009 Construction Facing Worldwide Challenges. Dubrovnik, September, 27-30. 2009, pp. 281-285.

11. Shirur ES, Torgal S. India construction industry challenges for the construction managers. IOSR J Bus Manag. 2014;16(4):65-9.

12. Lien M. Five main problems in the construction industry in the USA. 2017. NLB. https://mcahnicslien.com.

13. Rwelamila PD, Ogunlana S. W107-construction in developing countries research roadmap_report for consultation. In: International Council for Research and Innovation in Building (CIB). 2015.

14. Hillebrandt PM. Economic theory and the construction industry. London: Macmillan; 2000.

15. Schalcher RH. Complexity in construction. ResearchGate. www.researchgate.net/.2015.

16. Geraldi JG. The balance between order and chaos in multi-project firms: a conceptual model. Int J Project Manage. 2008;26:348-56.

17. Wells J. Informality in the construction sector in developing countries. Constr Manag Econ. 2007;25(1):87-93.

18. Handy CB. Understanding organisations. 4th ed. London: Penguin; 1993.

19. World Economic and Social Survey. Sustainable development challenges. U.N. Publication; 2013. Accessed: 3 Apr 2019.

20. Serpell A, Kort J, Vera S. Awareness, actions, drivers and barriers of sustainable construction in Chile. Technol Econ Dev Econ. 2013;19(2):272-88.

21. Susan Dzifa Djokoto SD, Dadzie J, Eric Ohemeng-Ababio E. Barriers to sustainable construction in the Ghanaian construction industry: consultants perspectives. J Sustain Dev. 2014;7(1)

22. Ametepey O, Aigbavboa C, Ansah K. Barriers to the successful implementation of sustainable construction in the Ghanaian construction industry. In: 6th International Conference on Applied Human Factors and Ergonomics (AHFE 2015) and the Affiliated Conferences, AHFE. 2015

23. Hasan MSMS, Zhang R-J. Critical barriers and challenge in implementation of green construction in China. Int J Curr Eng Technol. 2006;6(2):435-45.

24. Davis OOA, Davies IOE. Barriers to implementation of sustainable construction techniques. MAYFEB J Environ Sci. $2017 ; 1$ (2):1-9.

25. Aghimien D, Aigbavboa C, Oke A, Musenga C. Barriers to sustainable construction practices in the zambian construction industry. In: Proceedings of the International Conference on Industrial Engineering and Operations Management Paris, France, 2018;26-27, 2018.

26. McCool SF, Stankey GH. Indicators of sustainability: challenges \& opportunities at the interface of science and policies. Environ Manage. 2004;6:93-105.

27. Jaiyesimi R. The challenge of implementing sustainable development goals in Africa: the way forward. Afr J Reprod Health (special edition on SDGs). 2016;20(3):13-8.

28. Bryman A, Bells C. Business research methods. Oxford University Press; 2007.

29. Aveyard H. Doing a literature review in health and social care. London: McGraw Hill; 2007.

30. Aghimien DO, Adegbemo TF, Aghimien IE, Awodele AO. Challenges of sustainable construction: a study of educational buildings in Nigeria. Int J Built Environ Sustain. 2018;5:33-46.

31. Mahamid I. Factors affecting contractor's business failure: contractor's perspective. Eng Constr Archit Manag. 2012;19(3):269-85.

32. Ofori G. Nature of construction industry, its needs, and its development: a review of decades of research. J Constr Dev Countries. 2015;20(2):115-35.

33. Snyder H. Literature review as a methodology: an overview and guidelines. J Bus Res. 2019.

34. Covington MV. Goal theory, motivation, and school achievement: an integrative review. Annu Rev Psychol. 2000;51:171-200.

35. Gross JJ. The emerging field of emotion regulation: an integrative review. Rev Gen Psychol. 2000;2:271-99. https://doi.org/10.1037/10892680.2.3.271.

36. Mazumdar T, Raj SP, Sinha I. Reference price research: review and propositions. J Mark. 2005;2005(69):84-102. https://doi.org/10.1509/ jmkg.2005.

37. Guidelines and examples. Literature reviews. Hum Resour Dev Rev. 2005;4:356-67. https://doi.org/10.1177/1534484305278283. 
38. UNSD. Agenda 21, United Nations Conference on Environment and Development. Rio de Jeneiro, Brazil; 1992.

39. Kibert CJ. Final Session of First International Conference of CIB TG16 on Sustainable Construction, Tampa, Florida, November; 1994.

40. Du Plessis C. Agenda 21 for Sustainable Construction in Developing Countries. CSIR Report BOU/E0204, CSIR, CIB \& UNEP-IETC, Pretoria; 2002.

41. Du Plessis C. A strategic framework for sustainable construction in developing countries. Constr Manag Econ. 2007;25:67-76.

42. CEM. Sustainability and the Built Environment. www.cem.ac. UK; 2008.

43. McGranahan G, Satterthwaite D. Environmental health and ecological sustainability: reconciling the brown and green agendas in urban development. In: Pugh C, editor. Sustainable cities in developing countries, Earthscan, London; 2000.

44. ICC. Green economy roadmap and ten conditions for a transition toward a green economy. Sustainable Development Knowledge Platform; 2015.

45. UNESCO. Education for Sustainable Development. 2017; http://en.unesco.org/themes/education-sustainable-development. Accessed 15 Mar 2018

46. OECD. Working with change: systems approaches to public sector challenges. OECD observatory of Public Sector Innovation. E.U.; 2017.

47. Draper F. A proposed sequence for developing systems thinking in a grades 4-12 curriculum. Syst Dyn Rev. 1993;9:207-14 (CrossRef).

48. Ison R. How to act in a climate change world. Milton Keynes, UK: Springer; 2010.

49. ILO. Developing the construction industry for employment-intensive infrastructure investments. EIIP. (2019).

50. Lundin RA, Söderholm A. A theory of temporary organization. Scand J Manag. 1995;11(4):437-55.

51. Cloud JP. Some systems thinking concepts for environmental educators during the decade of education for sustainable development. In: Chalkley B, Haigh M, Higgitt D, editors. Education for sustainable development, Routledge: New York. NY: USA; 2009. p. $225-9$.

52. Checkland P. Systems thinking, systems practice. In: Pyster, Arthur, editor. 2012. Systems Engineering Body of Knowledge. 1.0 edn. Wiley, Stephens Institute and the Naval Postgraduate School; 1999.

53. 21839-2019-ISO/IEC/IEEE International Standard—Systems and software engineering-System of systems (SoS) considerations in life cycle stages of a system; 2019.

54. CIB. Managing Construction Industry Development in Developing Countries: Report on the First Meeting of the CIB Task Group 29. Arusha, Tanzania, 21-23 September. Rotterdam. In: Ofori. Indicators for measuring construction industry development. 2000. Building Research and Information. 1999;29(1):40-50.

55. Ofori G. The construction industries in developing countries: strategic review of the book. In: Ofori G, editor. New perspectives on construction in developing countries. Spon: Abingdon; 2012. p. 1-15.

56. World Economic Forum. Shaping the future of construction: a breakthrough in mindset and technology. Prepared in collaboration with the Boston Consulting Group; 2016.

57. Taherdoost, H. Validity and reliability of the research instrument; how to test the validation of a questionnaire/survey in a research. Int $J$ Acad Res Manage (IJARM). 2016;5(3).

Publisher's Note Springer Nature remains neutral with regard to jurisdictional claims in published maps and institutional affiliations. 